ANALES DE LA UNIVERSIDAD DE ALICANTE. HISTORIA MEDIEVAL, n. ${ }^{\circ} 20$ (2017-2018): 163-185

DOI:10.14198/medieval.2017-2018.20.06 I.S.S.N.: 0212-2480

Puede citar este artículo como:

Franco Sánchez, Francisco. «El sistema defensivo almohade del interior del Šarq al-Andalus frente a los cristianos. Origen, reestructuración y paralelos del sistema fronterizo de Albacete y Sur de Valencia (s. XII)». Anales de la Universidad de Alicante. Historia Medieval, N. 20 (2017-2018): 163-185, DOI:10.14198/medieval.2017-2018.20.06

\title{
EL SISTEMA DEFENSIVO ALMOHADE DEL INTERIOR DEL ŠARQ AL-ANDALUS FRENTE A LOS CRISTIANOS. ORIGEN, REESTRUCTURACIÓN Y PARALELOS DEL SISTEMA FRONTERIZO DE ALBACETE Y SUR DE VALENCIA (S. XII)
}

\author{
Francisco Franco Sánchez \\ Catedrático de Estudios Árabes e Islámicos \\ Universidad de Alicante \\ ffransan@ua.es
}

\section{RESUMEN:}

Se enuncian las principales características de los dos tipos de sistemas de control y defensa en al-Andalus: El sistema defensivo de control vial extendido en época omeya (ss. VIII-X) y el posterior sistema defensivo de carácter reticular implantado en la época almohade (s. XII). Se dedica especial atención a describir la frontera almohade en el Norte de la Mancha Oriental e interior de Valencia. En este aspecto es esencial la crónica de Ibn Șāhib al-Ṣalā (m. 1182) titulada Al-Mann bi-l-imāma en que se describe cómo el califa almohade Abū Ya'qūb Yūsuf, a su regreso de la Campaña de Huete del 167 H./1172 e.C., durante su estancia en Murcia, tras recibir la sumisión de Ibn Mardaniš a la causa almohade, procede a la reforma administrativa y de las fronteras del Šarq al-Andalus. Se concluye que Ibn Mardanīš, tras su sumisión, les cede a los almohades esta frontera. Finalmente se aportan los datos de las circunscripciones administrativas almohades de la Mancha Oriental: Chinchilla, Villena, Peñas de San Pedro, sistema defensivo del Júcar, Alcaraz y Segura de la Sierra. Para concluir, se enuncia una lógica geopolítica para la conquista castellana de La Mancha Oriental y Murcia. 
Palabras claves: Mancha Oriental, sistema defensivo almohade, Ibn Ṣāhib al-Șalā, califa almohade Abū Ya'qūb Yūsuf, ejército almohade.

\section{ABSTRACT:}

The main characteristics of the two kind of control and defence systems in al-Andalus are set out: the defensive system of road control extended in the Umayyad period (8th-10th centuries) and the later defensive system of a reticular nature implemented in the Almohad period (12th century). Special attention is given to describe the Almohad wide frontier in the North of the Eastern Mancha and South of Valencia. For this purpose it is essential the chronicle of Ibn Șāhib al-Ṣalā (m. 1182) entitled Al-Mann bi-l-imāma in which it is described how the Almohad caliph Abū Ya'qūb Yūsuf, on his return from the Huete Campaign of 167 H./1172 e.C., during his stay in Murcia, after receiving the submission of Ibn Mardaniš to the Almohad cause, proceeds to reform this frontier of the Šarq (East) al-Andalus. It is concluded that Ibn Mardaniš, after his submission, cedes this border to the Almohads. Finally, the data of the Almohad administrative districts of the Eastern Mancha are summarized: Chinchilla, Villena, Peñas de San Pedro, the Júcar defensive system, Alcaraz and Segura de la Sierra. To conclude, a geopolitical logic for the Castilian conquest of La Mancha Oriental and Murcia is stated.

Key words: East of La Mancha, Almohad defensive system, Ibn Șāhib al-Ṣalā, Almohad caliph Abū Ya'qūb Yūsuf, Almohad army.

\section{INTRODUCCIÓN ${ }^{1}$}

Desde el año 1993 en que lo tratamos en nuestra Tesis Doctoral, hemos venido profundizando y publicando sobre diversos aspectos relacionados con la relación entre vialidad y caminos con defensa y fortalezas a lo largo de los diversos períodos de la historia andalusí en la península Ibérica. ${ }^{2}$ Mientras

1 Este estudio se ha desarrollado dentro del Proyecto de Investigación del Plan Nacional $\mathrm{I}+\mathrm{D}+\mathrm{I}$ «Redes sociales y proyección económica en una sociedad de frontera: el Sur del reino de Valencia entre los siglos XIII-XV» (DGIYG del MIC, Ref.: HAR2010-22090).

2 Las principales ideas aquí expuestas ya han sido avanzadas en otros estudios que han tratado previamente sobre este tema y sobre otros conexos: Francisco FRANCO SÁNCHEZ: Vías y defensas andalusies en la Mancha Oriental, Alicante, ed. Instituto de Cultura Juan Gil Albert / Generalitat Valenciana (Col. Textos Universitarios), 1995, 402 pp. + láms.; ibid.: «El estudio de las vías en época andalusí: Consideraciones metodológicas, históricas y administrativas», Caminería Hispánica. Actas del V Congreso Internacional de Caminería Hispánica. Celebrado en Valencia (España) Julio 2000. Tomo 
que sobre caminos y vías andalusíes casi nada más se ha escrito, en cambio, mucho se ha publicado desde entonces acerca de castillos y fortalezas de al-Andalus, especialmente con un abordaje desde la perspectiva de la arqueología, poniendo también énfasis en las líneas de defensa, ${ }^{3}$ así como en la creación y fundación de fortalezas, ${ }^{4}$ o sobre el derecho relacionado con ellas, ${ }^{5}$ según lo refieren las fuentes árabes.

He creído conveniente volver sobre un tema que ya traté hace bastantes años, pero que quiero nuevamente reconsiderar, porque no he vuelto a ver que nadie se haya ocupado del mismo, ni nadie haya replanteado nuevas perspectivas para lo que voy a volver a exponer recuperando las líneas maestras sobre el origen y reestructuración por parte de los almohades de la frontera interior del Sur de Valencia y del Norte de Albacete actuales frente al imparable avance de los cristianos en el siglo XII. ${ }^{6}$

II: Caminería Histórica y Turística. Dirección: Manuel Criado de Val, Valencia, ed. Patronato Arcipreste de Hita / C.E.D.E.X. / C.E.H.O.P.U. (Ministerio de Fomento), 2002, pp. 865-888; e ibid.: «La caminería en al-Andalus (ss. VIII-XV J.C.): Consideraciones metodológicas, históricas y administrativas para su estudio», TST. Transportes, Servicios y Telecomunicaciones, Madrid, ed. Fundación de los Ferrocarriles Españoles, $\mathrm{n}^{\circ}$ 9, 2005, pp. 34-64.

3 Hay que recordar aquí los trabajos del malogrado Peter C. Scales sobre las líneas de defensa del Ebro.

4 Remitimos a los trabajos de los Profs. Juan Antonio Souto Lasala, recientemente fallecido, o del propio Antonio Malpica para el reino de Granada, a los que se podría añadir otros nombres más como Sonia Gutiérrez, Rafael Azuar, María Jesús Viguera, en una nómina bibliográfica bien extensa, aunque también muy centrada en ámbitos muy restringidos tanto geográficamente, como cronológicamente.

5 Sobre lo cual hemos publicado Manuela Marín y yo mismo.

6 Publicado como Francisco FRANCO SÁNCHEZ: «La frontera alternativa: Vías y enfrentamientos islamo-cristianos en la Mancha Oriental y en Murcia», Actas del Congreso La Frontera Oriental Nazarí como sujeto histórico (ss. XIII-XVI). Lorca-Vera, 22 a 24 de noviembre de 1994. Coord. por Pedro Segura Artero, Almería, ed. Instituto de Estudios Almerienses, 1997, pp. 237-251. No hemos de dejar de apuntar que sobre esta zona del Júcar se han publicado con posterioridad importantes estudios centrados, tanto en su historia medieval (como Aurelio PRETEL MARÍN: Del Albacete islámico: Notas y conjeturas, Albacete, ed. Instituto de Estudios Albacetenses «Don Juan Manuel» de la Diputación de Albacete, 2007, 224 pp., ibid.: «Alcalá del Río Júcar: del Islam al concejo castellano», Alcalá del Júcar: Piedra, tierra, agua y sus gentes. Gregorio López Sanz (coordinador), Albacete, ed. Instituto de Estudios Albacetenses «Don Juan Manuel», 2014, pp. 87-112, ibid.: Conquista y poblamiento del Júcar de Albacete. Edición conmemorativa del VIII Centenario de la primera conquista, Albacete, ed. Fundación Caja Rural, 2017, 56 pp.), como también en la arqueología local (como José Luis SIMÓN GARCÍA: «El poblamiento islámico de las tierras de Alcalá del Júcar (siglos VII al XIII)», Alcalá del Júcar: Piedra, tierra, agua y sus gentes. Gregorio López Sanz (coordinador), Albacete, ed. Instituto de Estudios Albacetenses «Don Juan Manuel», 2014, pp. 53-83; José Luis SIMÓN GARCÍA, Pedro JIMÉNEZ CASTILLO: «El poblamiento andalusí en las tierras de secano: el área sudoriental de La Mancha (ss. 
Seguidamente vamos a centrarnos en las características esenciales de los sistemas de control de los espacios (o sistemas defensivos) de la época mardanīšì y almohade en los territorios de la Mancha Oriental, es decir, llanuras de la actual Albacete y territorios de las vecinas regiones montuosas del Norte de la actual provincia de Murcia, interior de la de Alicante, Suroeste de Valencia, Sur de Cuenca, y Norte de Jaén. ${ }^{7}$

\section{LOS DOS TIPOS DE SISTEMAS DE CONTROL Y DEFENSA EN AL- ANDALUS: EL DEL ESTADO OMEYA Y EL DE ÉPOCA ALMOHADE}

\subsection{El sistema defensivo de control vial extendido en época omeya}

La venida desde Damasco y acceso al poder en al-Andalus del omeya 'Abd al-Raḥmān I al-Dājil (el "Inmigrado", 138-172 H. 756-788 d.C.) traerá como consecuencia una profunda renovación política, administrativa, militar y de muchos otros aspectos del aún incipiente estado andalusí. Concretamente en la faceta material, Aḥmad al-Rāzī nos dice que este emir «fizo los arrezifes ${ }^{8}$ e las buenas calzadas que van de las vnas villas a las otras». ${ }^{9}$ También durante su reinado se instauró el que denominamos como sistema de control y defensa omeya. ${ }^{10}$

Así, desde el 138 H./756 d.C. se van extendiendo por al-Andalus unos sistemas de control de los espacios consistentes en líneas de fortalezas y almenaras comunicadas con ellas, que se superponen a los más importantes tramos itinerarios peninsulares. Se trata, en primer lugar, del control militar

XI-XIII)», Al-Qanțara, XXXVIII, n. 2 (2017), pp. 215-259), pero, ni estos, ni otros trabajos que han tratado más tangencialmente del valle del río Júcar, han tocado el objetivo del presente trabajo, que es su papel histórico esencial en el siglo XII como frontera interior (primero mardanīšñ luego almohade) del Šarq al-Andalus frente a las acometidas militares de castellanos y aragoneses.

7 Para no caer en anacronismos administrativos, preferimos usar un enunciado geográfico -"La Mancha"- a otro administrativo muy posterior -provincia de Albacete-, motivo por el que para denominar la región enunciada preferimos hablar de "Mancha Oriental" (sin olvidar que las llanuras albacetenses están indisolublemente unidas al anfiteatro montañoso que las rodea, unidas orográfica y vialmente, como veremos).

8 De al-rasiif "el pavimento", en alusión a calzadas pavimentadas. Esta palabra árabe hoy designa a las aceras.

9 Versión romance del s. XIV de los Ajbār mulūk al-Andalus, conocida como Crónica del Moro Rasis, editada por Diego CATALÁN; Ma. Soledad de ANDRÉS, et alii, Madrid, ed. Gredos, 1975, p. 371.

10 Cfr. $\mathrm{M}^{\mathrm{a}}$. Jesús RUBIERA: Villena en las calzadas romana y árabe, Alicante, ed. Ayuntamiento de Villena / Universidad Alicante, 1985, pp. 49-55, y F. FRANCO SÁNCHEZ: Vías y defensas, passim. 
y de la defensa -que preferimos denominar como espacios defensivos-, con acantonamiento de tropas y vigilancia militar de la región. También desde ellos se ejerce un control civil, puesto que desde estos enclaves se recaudan impuestos, en algunos de ellos residen los gobernadores locales y, en general, se garantiza la tranquilidad de la vida económica regional.

Esta necesidad de control y supervisión de las comarcas y regiones fronterizas se concretó especialmente en dos grandes sistemas, dos auténticos espacios fronterizos: uno marino (mediterráneo), y otro terrestre (los thugūr, frente a los cristianos del Norte). Conforme a lo expresado, son de tipo vial, hallándose asentados a lo largo y en torno a las dos principales vías de época romana: la Vía Augusta -con su ramal interior manchego, el conocido como Camino de Aníbal- y la vía Córdoba-Toledo-Zaragoza, respectivamente.

La frontera marítima, articulada como "vial" en torno a la Vía Augusta, tuvo su origen en la lucha frente a los 'abbāsīes de Oriente, y supone un "filtro" frente al Mediterráneo. El mar de enmedio (al-baḥr al-abyạ̣ almutawassiț) sigue siendo camino de unión con el resto del mundo islámico, ante el cual es obligado instaurar una barrera fronteriza que controle la entrada a través de las amplias costas del Šarq al-Andalus. ${ }^{11}$ La situación geopolítica se reproduce y acentúa por la proximidad, con el advenimiento al poder en Túnez de la dinastía de los fātimìes, desde comienzos del s. IV/X. ${ }^{12}$ La conciencia de frontera es afirmada por el propio Ibn Hawqal, viajero, comerciante e informador interesado (si no espía), que en el siglo IV/X, habla explícitamente del litoral mediterráneo como «región fronteriza (hadda)». ${ }^{13}$

11 Cfr. los pormenores en nuestro libro Vías y defensas... Desde un enfoque geográfico, abordamos esta idea del Mediterráneo como mar-camino de unión con los países ribereños en el estudio «Al-Andalus como isla del Mediterráneo. Presupuestos mentales e islamológica en las primeras representaciones árabes de la Península Ibérica», Revista del Instituto Egipcio de Estudios Islámicos en Madrid, XXVI (1993-1994), pp. 187-241, en él se recogen las fuentes árabes y bibliografía en que se fundamentan estos asertos.

12 Ver de Míkel de EPALZA: «Importancia de la historia árabe de Denia», Dianium, 1 (1982), pp. 45-89; id. Orígenes de la invasión cordobesa de Mallorca en 902», Estudis de Prehistòria, d'Historia de Mayūrqa i d'Història de Mallorca dedicats a G. Rossello Bordoy, Palma de Mallorca, 1982, pp. 111-129; ibid. «Problemas y reflexiones sobre el califato en al-Andalus», Homenaje al Profesor Abdelaziz al-Ahwānī. Revista del Instituto Egipcio de Estudios Islámicos en Madrid, 18 (1981-1982), pp. 59-73; «El esplendor de al-Andalus, reflejo del esplendor fatimí en el siglo XI/V», Actas del IV Coloquio Hispano-Tunecino (Palma de Mallorca, 1979), Madrid, ed. I.H.A.C., 1983, pp. 79-82.

13 IBN ḤAWQAL: Kitāb șūrat al-ard, primera ed. ár. de M. J. de GOEJE: Bibliotheca Geographorum Arabicorum. Pars Secunda. Viae et Regna. Descriptio Ditionis Moslemicae, auctore Abu'l-Kásim Ibn Haukal, Lugduni Batavorum, ed. E. J. Brill, 1873, p. 75; segunda ed. ár., más completa, de J. H. KRAMERS: Opvs Geographicvm auctore Ibn Hawkal (Abū l-Kāsim Ibn Hawkal al-Nașībī), Leiden, ed. E. J. Brill, 1938, pp. 109. Ed. de Beirut, Manšūrāt Dār Maktabat al-Ayāt, 1978, p. 105. 
En el caso de las fronteras terrestres, el sistema omeya funciona de modo similar. Sobre las tierras al Norte de los ríos Tajo y Ebro las vías se constituyen como un tejido venoso por el que transitan comunicaciones frecuentes entre el Norte y el Sur. Las vías de comunicación, muy controladas mediante los sistemas de defensa y control, indisolublemente unidos a ellas, son las arterias por las que fluye el indispensable tráfico comercial, de mercancías, personas, ideas y ciencia entre las sociedades de la Península. Las líneas de comunicaciones, vitales y por ello muy controladas, son los antiguos ejes de dirección N-S. ${ }^{14}$ Nada tiene que ver este sistema con el tradicionalmente conocido como el desierto estratégico, o el desierto del Duero que defendiera $\mathrm{Cl}$. Sánchez-Albornoz y su escuela, ${ }^{15}$ interpretación que en los últimos tiempos está desmintiendo también la arqueología.

En el caso de la frontera marina, el Mediterráneo es ante todo, un camino de unión, y nunca actúa como tal desierto estratégico; más bien al contrario, el mar siempre acerca, une, independientemente de las circunstancias geopolíticas. Es precisamente para impedir la entrada por las extensas costas mediterráneas para lo que se instaura el sistema de control y defensa omeya.

Ambas fronteras -terrestre y marina- se fundamentan en el mismo principio: impedir que penetren los cuerpos militares organizados, por medio del estricto control de las entradas y las salidas del territorio musulmán. Se trata de frenar la entrada, pero no con un sistema de barrera impermeable (como el de la famosa muralla china), sino mediante una zona fronteriza permeable y bien controlada. Esta permeabilidad se permitía únicamente a través de unos espacios determinados: las vías de comunicación de origen romano, y -en segundo lugar- por los valles fluviales. ${ }^{16}$ Por ello, los referidos espacios viales a su vez se hallaban ligados a unos sistemas de defensa y control de los mismos.

La razón última del sistema se encuentra en la menor -que no inexistente- densidad poblacional que había, no sólo en las propias fronteras Superior,

14 Ver al respecto Francisco FRANCO SÁNCHEZ: «Aportaciones al estudio de las vías de época islámica en la Meseta Norte», Proyección histórica de España en sus tres culturas: Castilla y León, América y el Mediterráneo. Coord. E. Lorenzo Sanz, Valladolid, ed. Consejería de Cultura y Turismo de la Junta de Castilla y León, Vol. I, 1993, pp. 73-87.

15 Ver el desmentido de su existencia que Ibn al-Kardabūs (s. VI-VII/XII-XIII) pone en boca de Ibn Abī 'Āmir: IBN AL-KARDABŪS: Kitāb al-iktifā' fì ajbā al-julafă', ed. ár. de Amad Mujtār AL-'ABBĀDĪ: «Historia de al-Andalus, por Ibn al-Kardabūs y su Descripción por Ibn al-Šabbāț̣, Revista del Instituto Egipcio de Estudios Islámicos en Madrid, XIII (1965-1966), pp. 64-65.

16 Sobre la importancia de los valles fluviales como espacios viales, y sobre los espacios de control y defensa a ellos asociados para su supervisión, cfr. Francisco FRANCO SÁNCHEZ: «En torno de la ubicación de la fortaleza islámica de Qalașat: La importancia económica y estratégica del río Júcar», Espacio. Tiempo y Forma. Serie III. Historia Medieval. Homenaje al Prof. Eloy Benito Ruano, Serie III, n. 1 (1988), pp. 193-206. 
Media e Inferior, sino en las regiones cercanas de la Meseta Norte o territorios de Aragón y Cataluña.

Este tipo de fronteras de época omeya perdurará en su lógica de funcionamiento y en su estructura durante el período de los reyes de taifas, aunque territorialmente fragmentado, pero cambiará cuando los almohades se hagan con el control de al-Andalus. Un primer cambio se produjo con los almorávides y su sistema militar: reaparecen los grandes ejércitos, combatiendo en formación cerrada; los cambios militares y defensivos que pudieran haber generado en al-Andalus aún no son bien conocidos (aunque pensamos que fueron escasos).

\subsection{Un nuevo sistema defensivo en época almohade de carácter reticular}

2.2.1. Entre otras muchas novedades, los almohades introdujeron un nuevo ordenamiento administrativo, novedosos modos de lucha y defensa militares, articulando también un nuevo tipo de fronteras acordes con estas concepciones.

La reorganización administrativa almohade tiene su fundamento en una nueva concepción del papel de la ciudad (madinna), que junto a su alfoz (alhawz o término jurisdiccional) pasan a ser los elementos esenciales sobre los que se estableció esta concepción menos "provincial" que la precedente de época omeya y más "comarcal". La ciudad y su hinterland o espacio periurbano, pasará a ser la administradora de las funciones de la religión, administración, política y ejército, etc. Cada término jurisdiccional dependiente de una ciudad importante será también una unidad administrativa, un partido judicial con juez ( $q \bar{a} d \bar{l})$ propio, y también una unidad militar autónoma, aunque interdependiente de las unidades limítrofes con ella.

De este modo se configura un tejido de comarcas con capitales en las que hay tropas acuarteladas. Éstas tenían una serie de funciones: En primer lugar, el control de las poblaciones locales de cada comarca y sus a'mal (o circunscripciones dependientes); las poblaciones locales habían crecido considerablemente y el peligro más frecuente estaba en los levantamientos locales.

En segundo lugar, se trataba de recaudar impuestos y controlar los ataques de las partidas de bandoleros armados que asolaban determinadas regiones, en especial las montañosas (para ello se establecen fortalezas secundarias con tropas en estas regiones más alejadas).

En tercer lugar, cuando la conquista cristiana las sitúa en primera línea de defensa, esta red militar actúa como un panal de abeja interconectado reticularmente, de modo que los ejércitos cristianos han de ir conquistando una a una estas circunscripciones comarcales almohades. 
2.2.2. Las fronteras en la época almohade son de un único tipo: son terrestres, únicamente ya frente a los cristianos del interior. La frontera marina deja de tener el sentido estratégico que poseía en época omeya.

Hay además una nueva característica: frente a la relativa perduración a lo largo de los siglos IX hasta el inicio del XI, de los $\underline{t} u g \bar{u} r$ terrestres de tipo omeya, los almohades organizan unos sistemas defensivos que presentan una nueva variable: son además dinámicos. En su concepción original esta circunstancia debía hacer posible -en principio- su extensión a cualquier territorio. El mismo sistema ha de ser aplicable a diferentes zonas. Responden a una lógica y situación geopolítica diferentes, siendo, por ello, reflejo de una nueva situación militar y de una nueva concepción de los sistemas de control y defensa.

Un cambio esencial es que ya no existen zonas-colchón con menor densidad de población, como en la época omeya. Al contrario, en las tierras de la submeseta meridional y como consecuencia del auge demográfico de los ss. IV/X al VI/XII (auge tanto vegetativo, como -esencialmente- consecuencia de las oleadas de musulmanes que emigran hacia el Sur por la conquista), existe una densa población en la mayor parte de las regiones, especialmente el Šarq al-Andalus y la Bética.

Los cambios reseñados, conjugados con la evolución de los modos de combate (uso general de la caballería ligera, nuevas armas, etc), obligaron a un sistema más cerrado de control. Es por ello que las ciudades (junto con sus alfoces -del árabe al-hawz, "territorio jurisdiccional"-), como centros de poder político, administrativo y militar, pasan a convertirse en las células básicas, que configuran una trama administrativa, a la vez que una red de nódulos militares entrelazados, los cuales, en combinación con las vías de comunicación pasan a conformar unos sistemas defensivos ya de carácter bien diferente a los anteriormente conocidos.

El sistema almohade, en vez de "lineal" puede definirse mejor como "reticular" o, mejor, "en panal de abeja". Estaba conformado por una red de ciudades, con sus almenaras y castillos de control enlazados a ellas, y por una red de caminos, de vías andalusíes que mantenían esta unión ya no solo lineal, sino reticular y centrada en las cabezas del sistema "en panal de abeja". Este sistema defensivo se asienta en al-Andalus en fortalezas situadas en promontorios más bajos, más cercanos a las ciudades, y aunque controlando los caminos, este control se ejerce desde una menor altura, con la ayuda de un gran número de atalayas que vigilan desde la inmediatez los accesos a estas urbes almohades. La importancia del control vial no se ha atenuado, pero la caballería ligera, de fácil entrada campo a través, sí ha variado la 
ponderación de esta importancia. Junto a esta circunstancia, la relevancia que adquieren los caminos terreros secundarios ( $v$. gr. en los múltiples itinerarios del camino de Córdoba a Toledo $)^{17}$ y los caminos de montaña en el Šarq al-Andalus y la Bética, hicieron que el sistema tuviera otro carácter bien diferente al bizantino-omeya. ${ }^{18}$

Pero a la hora del análisis y de una profundización en el conocimiento de los sistemas de control de época almohade nos encontramos con el grave problema que supone la carencia de fuentes para su conocimiento. Las fuentes árabes de época almohade o posterior presentan tres serios escollos: primeramente, la singularidad de cada una de ellas (los datos que aportan y las circunstancias de su gestación cronística hacen que de estos textos sea difícil extrapolar su información a casos muy concretos); en segundo lugar, en ninguno de los textos conocidos se hacen más que alusiones incidentales a la región que nos ocupa. Muy escasas también son las referencias que encontramos en los diccionarios biográficos andalusíes; éstas hubieran podido servirnos para elaborar un mapa administrativo contemporáneo y detallado de la Mancha Oriental. ${ }^{19}$

2.2.3. La información de más calidad que poseemos sobre los sistemas de control y defensa almohades es la que nos transmite Ibn Ṣāḥib al-Ṣalā (m. 1182), ya que él mismo participó en la "Campaña de Huete" y pudo conocer personalmente la reforma de los sistemas, su funcionamiento y configuración. Por ello, entre los poco claros datos que poseemos sobre esta época, su crónica titulada Al-mann bi-l-imāma aporta una serie de informaciones de gran interés. La más importante es que los almohades heredan y asumen el sistema de frontera que creó Ibn Mardanīš para su estado independiente. ${ }^{20}$ No es un reacondicionamiento aislado de los sistemas defensivos de la frontera levantina y manchega, sino que se trata de una política planificada, centralizada y sistemática de los almohades. Conforme el poder almohade va reduciendo los focos de resistencia local o regional, se va haciendo con el mando de las zonas fronterizas, va nombrando a sus gobernadores militares, y va procediendo a una renovación de los espacios defensivos por regiones. En algunas

17 Cfr. el estudio de Félix HERNÁNDEZ JIMÉNEZ: «El camino de Córdoba a Toledo en la época musulmana», Al-Andalus, 24, n. 1 (1959), pp. 1-62.

18 Sistema articulado en torno a la Vía Augusta levantina o, en las fronteras, a la vía XXV del Itinerario de Antonino y la Vía de la Plata.

19 Siguiendo la metodología de Míkel de EPALZA: «L'ordenació del territori del País Valencià abans de la conquesta, segons Ibn al-Abbār (segle XIII)», Sharq Al-Andalus. Estudios Árabes, 5 (1988), pp. 41-67.

20 Como se desarrolla con detalle en el § 3, vide infra. 
ocasiones se aprovechan de los castillos, y de los gobernadores prexistentes, puesto que eran ellos quienes mejor conocían sus regiones.

Según nos refiere el cronista, el califa almohade durante sus estancias en al-Andalus prestó una gran atención a la reconstrucción de los sistemas fronterizos y fortalezas. Así ordenó «fortificar sus fronteras» en la zona de Córdoba, y en Sevilla «tranquilizó [las poblaciones de] las fronteras desiertas, contra los ataques de los cristianos y reconstruyó todos sus muros, y las devolvió al islam después de que estaban desiertas»; ${ }^{21}$ en otros lugares construyeron nuevas fortalezas cuando se hacía necesario, como es el caso de la alcazaba de Badajoz. ${ }^{22}$

2.2.4. También han de ser consideradas como fuentes de utilidad los documentos emanados especialmente de las cancillerías castellana y de la aragonesa. En ellos, en un buen número de ocasiones, se alude a una coyuntura a la que se da carácter de confirmación real, buscando sea continuación de la existente en la época almohade. Suele tratarse de documentos de confirmación de términos municipales (o alfoces, como castellanización del concepto almohade de al-hawz) en los que, al igual que en otros casos (v.gr. legislación sobre las aguas de las huertas de Murcia o Valencia; nombramientos de sobrecequieros o reparto de cargas para reparación y mantenimiento de murallas o acequias; confirmación de las iglesias mayores allí donde anteriormente estuvieron las mezquitas aljamas, etc.), se deja claramente indicado en ellos que las citadas confirmaciones se corresponden con el estado anterior a la conquista, es decir, con la situación administrativa del último período almohade.

Por ello, estas fuentes cristianas (aunque siempre con reservas), consideramos que aportan datos fiables acerca de la subestructura urbana y los elementos diversos que dependieron de cada uno de los espacios de control de la época almohade en el Šarq al-Andalus; eso sí, siempre que lo indiquen de modo explícito. No se trata de deducir nada de lo que pasó en la época islámica en base a estas fuentes cristianas, sino de utilizar sólo los datos que buscan reflejar la anterior realidad islámica, que hablan de la permanencia puramente formal de unas estructuras administrativas. ¿Por qué sólo estos y no otros datos? Por la garantía jurídica; hemos de pensar que si realmente se desea perpetuar una situación administrativa anterior, en caso de que los tér-

21 IBN ȘĀḤ̄̄B AL-ȘALĀ (m. 578/1182): Ta'rīj al-Mann bi-l-imāma 'alà al-mustaḍafīn bi-'an ŷa'ala-hum Allāh a’imma wa-ŷa'ala-hum al-wārițīn, ed. crítica árabe de Abdul Hadī AL-TĀZĪ, Beirut, ed. Dār al-Andalus, 1964/1383, pp. 206, 236, 293.

22 IBN ȘĀḤİB AL-ȘALĀ: Ta’rīj al-Mann bi-l-imāma, ed. árabe de Abdul Hadī AL-TĀZ̄̄, p. 236. 
minos enunciados no se correspondieran con la realidad previa, los intereses locales, movidos en defensa de sus prerrogativas, rápidamente se hubieran aprestado a reclamar el error.

Como hipótesis, podría aducirse que la razón última del deseo de pervivencia de unos muy concretos elementos jurídicos y administrativos de la época almohade (aunque sólo de modo formal y desprovistos del carácter propio que tuvieron en la época islámica) haya quizás que buscarlos en el deseo real del máximo control de todo tipo de donaciones y del ejercicio jurídico. En el caso del ejercicio jurídico la confirmación de una situación consuetudinaria anterior suponía una comodidad evidente, y un considerable ahorro de problemas la continuación de una tradición jurídica que centenariamente había demostrado su buena lógica. En el campo de la confirmación de alfoces, pensamos que hay que buscar la reafirmación del deseo de la corona del control real total de las donaciones, junto al deseo de ahorrarse los engorrosos problemas que acarreaban los pleitos entre municipios vecinos por cuestiones de términos. Si la reivindicación de algunas sedes episcopales se prolongó durante siglos, siendo causa de graves litigios, y tomando en cuenta que las bases argumentales más frecuentes eran las de haber sido sede episcopal ya antes de la conquista islámica, la confirmación de los mismos alfoces que en época islámica tuvieron determinadas ciudades, indicaría el deseo real de evitarse tales problemas.

Como consecuencia de lo apuntado, la estructura administrativa almohade (y los espacios defensivos anejos) habría pervivido a la propia dinastía almohade que los concibió y ordenó:

A. Por un lado, en tierras del reino de Aragón y castellanas (al menos en las šarqies), habría perdurado en alguna medida la ordenación espacial (no la estructural, aunque escasos datos haya sobre esto último), al ser asumida por los conquistadores cristianos. Lo indican los numerosos documentos de las citadas cancillerías que dejan explícito este origen: «assi como los auien en tiempo de los almohades» o «que fueron del termino de la villa ... en tiempo de Miramome». ${ }^{23}$

B. En otro ámbito cultural y espacial, la similitud de las estructuras de las tahas de la Granada nazarí con estas circunscripciones urbanas y sistemas defensivos almohades, -como hipótesis- llevan a deducir que estas tahas fueron uno más entre la multitud de elementos en que la personalidad nazarí fue una herencia y evolución de su precedente almohade.

23 Juan TORRES FONTES: C.O.D.O.M, Murcia, ed. Academia Alfonso X el Sabio, 1963, vol. I, 35, 39, 110; III, 83, 84; etc. 
2.2.5. Finalmente, el sistema de control y defensa de época omeya estaba destinado al control del movimiento de las personas (ya fueran comerciantes, lugareños, o tropas de paso) en su viaje a través de los caminos provinciales, asegurando los pasos estratégicos de esos mismos caminos, bien en los puentes o en las angosturas de los caminos en los montes. Está diseñado para el control del flujo de las gentes con el mínimo gasto humano (de ahí el situar los castillos y atalayas en las alturas) y la máxima eficacia en la transmisión de noticias, porque de eso se trataba, de la rápida comunicación de los peligros hasta el acantonamiento central del ejército más próximo.

En cambio, en el período almohade la caballería ligera y la intensa utilización de los caminos de montaña hacen inviable un control efectivo del flujo humano por los principales caminos, y a la vez dificulta y hace poco eficaz la transmisión de noticias, dada la velocidad de los cuerpos de caballería ligera. El sistema almohade tiene su sentido en el control de los asentamientos urbanos y periurbanos dependientes de los principales focos comarcales de ahí que las fortalezas se sitúen en un simple promontorio, por encima y alejado, pero cercano a las urbes que deben controlar y a las que recaudarán los impuestos obligados.

Es otra lógica de funcionamiento del sistema completamente diferente, por tanto, de la omeya, pero en cambio, su funcionamiento y operatividad será muy similar a la que heredarán los enclaves antes almohades cuando sean anexionados a los reinos de Castilla y de Aragón. Esta sería otra de las razones que cabría aducir para la permanencia de un statu quo administrativo y de la propiedad desde la época almohade a la posconquista.

\section{LA FRONTERA ALMOHADE EN EL NORTE DE LA MANCHA ORIEN- TAL E INTERIOR DE VALENCIA}

\subsection{Los espacios viales de la Mancha Oriental en la época almohade}

Durante el período del gobierno efectivo almohade no parece que hubiera cambios esenciales en el trazado general de las vías principales de la Mancha Oriental. ${ }^{24}$ El cambio va a venir determinado por la creciente importancia de algunos enclaves poblacionales de la montaña, que harán girar el peso de la importancia de los espacios viales hacia la montaña murciano-albacetense.

De esta época hay que destacar el texto árabe que refiere el itinerario militar de la expedición que en 567/1172 el califa almohade Abū Yacqūb

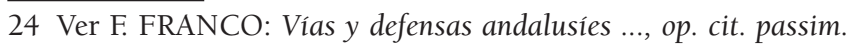


Yūsuf siguiera en su campaña contra las importantes fortalezas de Vilches, Alcaraz y Huete. ${ }^{25}$ Este recorrido reitera nuevamente la importancia militar del tradicionalmente conocido como Camino de Aníbal y vuelve a ser el eje esencial del itinerario de las tropas. El motivo por el cual los almohades se dirigieron a Huete, según Julio González estaba en la importancia que había adquirido este enclave en los últimos años, ya que su alfoz llegaba hasta el Júcar; los cristianos además habían avanzado mucho en dirección a Albarracín y Teruel; ${ }^{26}$ en su criterio, se trataba, de frenar su avance en dirección a Cuenca yendo primero a esta fortaleza, de «buena despensa y fácil acceso», siguiendo para ello el antiguo Camino de Aníbal. En nuestra opinión, el califa almohade buscaba dejar seguro y expedito el nudo vial que controlaba los caminos interregionales N-S (Aragón-La Mancha-Bética) y de E a O (rutas de Toledo a Valencia).

Por entonces pasa a ser la Mancha Oriental una región de frontera de gran relevancia, y la conquista cristiana, una vez que logra llegar a Despeñaperros y accede a la Bética (tras la campaña de Las Navas de Tolosa del 609/1212), centrará sus esfuerzos en dirección a la Mancha albacetense. En consecuencia, aparecen más noticias de la región en las fuentes cristianas. Esta región de la Mancha Oriental, como todas las que se transforman en fronteras, debió de sufrir algún tipo de transformación en los itinerarios que los musulmanes escogieron para sus viajes. No sabemos cuáles pudieron ser las mutaciones y cambios en los espacios viales de la época, aunque cabe apuntar que los itinerarios más alejados de las fronteras (situadas en este momento al Norte del Camino de Aníbal y del Júcar) fueron los más empleados. Este es el motivo que subyace en algunos itinerarios que atraviesan la región de la Mancha Oriental reflejados en el Uns al-Muhaŷ de al-Idrīsī (obra posterior al 548/1154); las descripciones de sus rutas son diferentes a las enumeradas en épocas anteriores, responderían a esta lógica fronteriza. ${ }^{27}$

25 IBN ȘĀḤ̂̄B AL-ȘALĀ: Ta’rīj al-Mann bi-l-imāma, ed. árabe de Abdul Hadī AL-TĀZ̄̄ pp. 487-514, especialmente pp. 490-2. Estudiado por Mª . Jesús RUBIERA MATA: «Los precedentes geopolíticos musulmanes del señorío de Villena», Congreso de Historia del Señorío de Villena. Albacete 23-26 octubre 1986, Albacete, ed. Instituto de Estudios Albacetenses / C.S.I.C., 1987, pp. 357-360. Cfr. nuestro estudio sobre Vias y defensas andalusíes en la Mancha Oriental, pp. 333-356.

26 Julio GONZÁLEZ: «Repoblación de las tierras de Cuenca», Anuario de Estudios Medievales, 12 (1982), p. 187.

27 AL-IDRĪSĪ (493-560/1099-100-1164.5): Uns al-muhây wa-rawd al-furaŷ, ed. crít. ár y trad. esp. de: Jassīm Abid MIZAL: Al-Idrīsī. Los caminos de al-Andalus en el siglo XII según "Uns al-Muhây wa-rawḍ al-furaŷ", Madrid, ed. C.S.I.C., 1989, 425 pp. Ver con más detalle en la segunda parte del libro sobre las Vías y defensas andalusíes, passim. 


\subsection{La reforma administrativa y de las fronteras del Šarq al-Andalus}

Las tierras šarqies desde comienzos del s. VI/XII sufrieron un gran cambio. Debido al avance de la conquista cristiana, pasan a ser una zona de primera línea de frontera. La nueva geopolítica determina todo un cambio de los espacios de control y defensa, no ya únicamente por el hecho de que el nuevo gobierno almohade imponga una nueva concepción de la defensa, sino por la nueva situación política con que se encontraron, relacionada con la premura y necesidad que imponía la cercanía y hostigamientos de los cristianos.

Hay una noticia transmitida por Ibn Șāhīib al-Ṣalā a la que hasta el momento no se ha prestado la debida atención. En ella nos refiere cómo se realizó la reforma administrativa, el cambio de los espacios de control y defensa del Šarq al-Andalus, y cómo esta profunda reestructuración se hizo de un modo calculado y planificado. Al regreso de la citada "Campaña de Huete" del 167/1172, tras conseguir llegar las tropas almohades del modo más penoso a Valencia y aprovisionarse en ella, el califa almohade Abū Ya'qūb Yūsuf y sus huestes siguen Vía Augusta (o al-Mahaŷŷat al-'Użmà), en un itinerario ya conocido, ${ }^{28}$ hasta llegar a la ciudad de Murcia. ${ }^{29}$

Este texto de Ibn Șāhẹib al-Ṣalā proporciona una valiosísima información acerca del funcionamiento de los espacios defensivos y de las fronteras en la época almohade. Del mismo podemos sacar tres grupos de datos: En uno primero, Ibn Șāḥịb al-Șalā nos informa que durante todo el mes de septiembre, en que el califa almohade residió en Murcia, su preocupación esencial fue la de reestructurar todos los espacios defensivos del Šarq al-Andalus: en palabras de propio Ibn Șāhịib al-Șalā «se cuidó de asegurar sus fortalezas y de enviar gobernadores a sus lugares de etapa y a sus castillos y de ocuparse en escribir (los nombramientos como gobernadores) a los favorecidos». La clave para la comprensión real de este texto está en la expresión árabe: «nazara fī tazqüf ma'āqili-hā», de la cual la palabra tazqüf es un mașdar de II Forma de la raíz >z_q_f $<$ ("ser" o "hacerse listo"), cuyo significado preciso es "formación, educación, instrucción"; con ello la frase transmite un significado más amplio que el propiamente de "asegurar". Más bien, está indicando cómo a los nuevos gobernadores confirmados o nombrados por los almohades se les "educa", se les "instruye", tanto en las características del nuevo sistema a implantar, como en la política militar almohade frente a la coyuntura bé-

28 Sobre la Vía Augusta en la época andalusí ver un análisis exhaustivo en F. FRANCO: Vias y defensas andalusíes ..., op. cit. passim.

29 IBN ȘẠ̄̄̂̄B AL-ȘALĀ: Ta'rīj al-Mann bi-l-imāma, ed. árabe de Abdul Hadī AL-TĀZĪ, p. 515. Resumida de modo genérico por IBN AL-ATIIR (554-630/1160-1233): AlKāmil fī l-tārīj, edición árabe de Beirut, ed. Dār al-Fikr, 1978, vol. IX, p. 165. 
lica. Creemos que debe interpretarse que en su estancia en Murcia el califa almohade departió con los gobernadores de sus castillos fronterizos con la finalidad de planificar una reestructuración de los sistemas defensivos, según las circunstancias lo estaban requiriendo. Aprovechó este mes de estancia en Murcia para conocer el estado general de los castillos de las fronteras, adaptarlos a una nueva concepción de las defensas y ordenar los reacondicionamientos necesarios.

No menos interés reviste la segunda parte de la frase: «wa-tawŷ̄hu l-walāt ilà manāzili-hā wa-ḥuṣūni-hāa, y se cuidó "de dirigir los gobernadores a sus manāzil y a sus ḥuṣūn" otorgándoles -como era preceptivo y costumbreun certificado escrito con sus nombramientos. No solamente se encarga de conocer el estado de las fortalezas, sino que el término «tawŷīhu» es "misión dada por el soberano a uno de sus empleados en una provincia", 30 entendiéndose que a partir de entonces se instauró una nueva dirección unificada de las fronteras del Šarq al-Andalus.

En segundo lugar «mandó que se presentasen Hilāl Ibn Mardanī̌̌ y sus hermanos, y su tío Abū l-Haŷŷâŷ Yūsuf en su sesión noble; los trató amablemente (...) y les prometió de su público y de su secreto lo que no alcanzó con al-Mā'mūn al-Hasan Ibn Sahl, y les indicó que ellos formarían parte de la comunidad almohade con la gente distinguida, y la familia (...)». Tras el reconocimiento de soberanía por parte de Ibn Mardanīš al califa almohade, son bien recibidos éste y sus tropas en la comunidad almohade; desde entonces contarán con su familia como importantes colaboradores para su política militar en el Šarq al-Andalus. Evidentemente, el conocimiento que Ibn Mardan̄̄šs tenía de los territorios que en tiempos fueran las antiguas coras de Tudmīr y Valencia se hacía insustituible para la defensa de estas regiones ahora fronterizas con los cristianos. Es, por tanto, también una colaboración interesada.

Finalmente «Confirmó a (su tío) Abū l-Haŷŷâŷ Yūsuf Ibn Mardanīš en Valencia y su región y le concedió el poder en sus distritos, porque conocía la sinceridad de su obediencia y su pureza y condiciones especiales. Del mismo modo, dejó a Abū 'Utimān Ibn Mūsà, el caíd, en el mando que tenía del castillo de Chinchilla y de su frontera, y confirmó a quien le pareció de los caídes de las fronteras y les colmó de bienes y favores, hasta hacerles olvidar lo que tenían antes con su emir, y entonces emprendió la vuelta». Este es quizás el fragmento de mayor relevancia para conocer cómo pudieron ser los espacios defensivos de la época almohade. Por un lado, reitera

30 Reinhardt P. DOZY: Supplément aux Dictionaires Arabes, Leiden-París, ed. E. J. Brill / G. P. Maisonneuve et Larose, 1967, $3^{\circ}$ ed., vol. II, p. 795. 
la noticia del nombramiento de un familiar de Ibn Mardanīš, Abū-l-Haŷŷâŷy Yūsuf Ibn Mardanīšs, como alcaide de la frontera de Valencia, de su región y de sus distritos, y por otro, confía a un militar, Abū 'Uțmān Ibn Mūsà, que ya gobernaba en Chinchilla, y confirma en su cargo militar. Es importante que el texto dice exactamente que era alcaide de «el castillo de Chinchilla y cualquiera (otro) hacia su frontera», es decir que Chinchilla era (al igual que en el período omeya) una de las capitales más importantes del sistema defensivo almohade de la Mancha Oriental.

Viene a completar este dato el mismo Ibn Șạ̄ị al-Ṣalā, cuando, tras la rendición de Ibn Mardanīš en 567/1172, acude éste y sus oficiales a prestar homenaje de sumisión al califa almohade y afirma el cronista: «luego le prestaron homenaje uno tras otro, precedidos por su jeque Abū 'Uțmān Sa'īd Ibn 'İsà, jefe de los soldados citados y señor de la frontera, se comprometieron a la obediencia y entraron en la comunidad [almohade]». ${ }^{31}$ Es decir, la sumisión de Ibn Mardanīš les vino muy oportuna a los almohades, puesto que heredaron y adaptaron el sistema defensivo propio que él había organizado; además, nos informa Ibn Șāhīib al-Ṣalā que aprovecharon sus conocimientos de la frontera y de la geopolítica de la guerra con los cristianos a la hora de llevar a cabo la remodelación de estos sistemas defensivos.

Es más, una vez reacondicionados los sistemas, restaurados los castillos, e instruidos en la nueva concepción de los mismos, confirma el califa en los puestos que ya ostentaban al tío de Ibn Mardanīš, y al antiguo caíd de la frontera de Chinchilla. La razón evidente es que, a pesar del cambio en la frontera, poseían estos unas fuerzas militares propias que ya venían garantizando su defensa y, por otro lado, conocían de las vicisitudes de la guerra con los cristianos mucho más que cualquier otro mando militar almohade. Por otro lado, confirmando a los caídes de los castillos y manteniendo sus tropas, eficaces por su conocimiento de la frontera, los almohades se evitan el tener que dejar acantonados soldados propios en esas lejanas fronteras.

A esta atención a la reconstrucción de los sistemas fronterizos y fortalezas se dedicó de un modo sistemático el califa almohade en sus estancias en alAndalus. Así lo hizo con las fronteras de la zona de Córdoba, de Sevilla, ${ }^{32}$ y de otros lugares, construyendo nuevas fortalezas cuando se hacía necesario, como es el caso de la alcazaba de Badajoz. ${ }^{33}$

No se trata de un reacondicionamiento aislado de los sistemas defensivos de la frontera levantina y manchega, sino de una política planificada,

31 IBN ȘĀHị̄B AL-ṢALĀ: Ta'rīj al-Mann bi-l-imāma, op. cit., p. 473.

32 IBN ȘĀḤ̄̄B AL-ȘALĀ: Ta'rīj al-Mann bi-l-imāma, op. cit., pp. 206, 236, 294.

33 IBN ȘĀHī̄B AL-ṢALĀ: Ta'rīj al-Mann bi-l-imāma, op. cit., p. 236. 
centralizada y sistemática de los almohades. Conforme el poder almohade va reduciendo los focos de resistencia local o regional, se va haciendo con el mando de las zonas fronterizas, va nombrando a sus gobernadores militares, y va procediendo a una renovación de los espacios defensivos por regiones. En algunas ocasiones se aprovechan de los castillos, y de los gobernadores preexistentes, puesto que eran ellos quienes mejor conocían sus regiones.

Al mismo tiempo y paralelamente se va introduciendo una reforma administrativa profunda, compleja y nueva, aún hoy escasamente conocida. ${ }^{34}$

\subsection{Las circunscripciones administrativas almohades de la Mancha Oriental}

La reorganización administrativa tiene su fundamento en una nueva concepción del papel de la ciudad, que junto a su alfoz (al-hawz) o término jurisdiccional, pasan a ser los elementos esenciales sobre los que se estableció esta concepción menos "provincialista" que la precedente de época omeya y más "comarcal". La ciudad y su hinterland o espacio periurbano, serán las unidades básicas depositarias de las funciones de la religión, administración, política, ejército, etc.

Probablemente la información de más calidad que poseemos sobre los sistemas de control y defensa almohades es la que nos transmite Ibn Șāhīb alȘalā (m. 578/1182), ya que él mismo participó en la "Campaña de Huete" y pudo conocer personalmente la reforma de los sistemas, su funcionamiento y configuración. Por ello, entre los poco claros datos que poseemos sobre esta época, su Al-mann bi-l-imāma aporta una serie de informaciones de gran interés.

\subsubsection{La "frontera de Chinchilla"}

En los párrafos precedentes ya se ha visto cómo Ibn Șāhịib al-Ṣalā en el itinerario de la campaña del 567/1172, se refiere a "la frontera de Chinchilla", aludiendo a esta localidad como una cabeza administrativa y militar, capital de la frontera homónima.

34 Vid. Míkel de EPALZA: «L'ordenació del territori del País Valencià abans de la conquesta, ...». Para la Mancha Oriental, consultar F. FRANCO: Vías y defensas andalusíes en la Mancha Oriental, segunda parte del estudio. Sobre la administración almohade véase las contribuciones de $\mathrm{M}^{a}$ Jesús VIGUERA MOLÍNS: «Historia política» (pp. 39123) y Rafaela CASTRILLO MÁRQUEZ: «Las instituciones. I. Instituciones políticas» (pp. 129-145) ambos en el volumen de El retroceso territorial de al-Andalus. Almorávides y almohades. Siglos XI al XIII. Vol. VIII-II de la Historia de España de Menéndez Pidal. Coord. Ma Jesús Viguera, Madrid, ed. Espasa Calpe, vol. VIII-2, 1997. 
También este mismo texto proporciona algunas notas topográficas al hablar de cada ciudad del itinerario; en base a éstas es posible definir la frontera con los cristianos en la fecha en que se efectúa la citada campaña. De cuatro de los lugares citados en el itinerario de las tropas almohades aporta una valiosa información: ${ }^{35}$

Según Ibn Șāḥīb al-Șalā, en Alcaraz, «Se encontró la gente con un castillo elevado (murtafa'ān), sobre un valle de grandes provechos ('alà buṭăh katīir al-manāfi'ā) y muchas aguas para regar sus campos (al-mazāri'a) porque se desliza alrededor de él el río llamado Guadalimar (wādī l-Ahmar)»;

Luego Balazote, Balāt Șūf (calzada de la lana, que no califica ni como castillo ni como ciudad), estaba en primera línea de frontera. En él toman agua las tropas;

En segundo lugar, es en el Júcar albacetense (probablemente cerca y controlando los puentes de Puente Torres o de Valdeganga), es donde acampa el califa almohade con sus huestes;

Más allá del Júcar ya parece ser tierra de cristianos, aunque sólo se afirma esto del desconocido lugar de Marŷy Jamal, la "vega de Jamal", que estaba «al principio del país de los cristianos». Por el arrasamiento que efectúan las avanzadillas almohades sobre el mismo no conocemos su ubicación.

Como consecuencia de estas referencias, la frontera parece situarse al Norte de la propia calzada andalusí que recorren los almohades: En ella se sitúa Balazote, al Norte del cual ya comienzan los lugares de los cristianos; Por el Este es más impreciso nuestro conocimiento de la frontera, debido a que no sabemos dónde estaba ubicado el citado Marŷ Jamal; Probablemente se situara al Norte de Iniesta, población que conocemos por otras fuentes geográficas y que hubiera sido citada por su nombre. Lo que sí sabemos es que el Júcar estaba cerca de esta "primera línea de frontera", que se extendería por tierras del Sur conquense e interior de Valencia, y que las tierras del Júcar albacetense serían, por tanto, una "segunda línea" o retaguardia.

Más tardío, el compilador Muhammad Ibn 'Abd al-Mun'im al-Șinhāŷ̄ al-Himyarī (s. VIII/XIV), en la entrada que dedica a «Ŷinŷāla» refiere la biografía del noble almohade Abū Zayd 'Abd al-Raḥmān Ibn Mūsā Ibn Waŷȳān (o Ibn Yūŷŷān) Ibn Yahyā al-Hintātī, que había sido visir del califa almohade al-Manșūr, tras lo cual fue encarcelado en Chinchilla, fortaleza de «aquella lejana frontera (tagr al-sahīq)», por el año 620/1224. ${ }^{36}$

35 IBN ȘĀḤİB AL-ȘALĀ: Ta’rīj al-Mann bi-l-imāma, op. cit., p. 491-2.

36 AL-ḦIMYARĨ (s. VIII/XIV): Kitāb ar-rawd al-mi'țār fī jabar al-aqtâr, ed. ár. y trad. fr. de los pasajes relativos a la península Ibérica y al Sudoeste francés de É. LÉVIPROVENÇAL: La Péninsule Ibérique au Moyen Áge d'après le "Kitāb Ar-Rawḍ al-mi'țār 
Las fortificaciones de Albacete, y Almansa estarían enlazadas, y ambas dependerían de la fortaleza chinchillana. Por otro lado, el «lugar (al-mawdi') conocido por Balazote (Balāṭ Șūf)» y la vía que conducía hasta las lagunas de Ruidera eran un límite fronterizo en el 567/1172.

\subsubsection{Villena}

En el itinerario de retorno del califa almohade Abū Ya'qūb Yūsuf de la mencionada "Campaña de Huete", va siguiendo la Vía Augusta, y acampa en el castillo de Villena (hiṣn Bilyāna), clara indicación toponímica que habla de su existencia como un castillo de una cierta importancia. Como la arqueología ha revelado, en el s. VI/XII hemos de considerar que se está hablando del castillo de La Atalaya, ${ }^{37}$ una fortaleza que desempeñará un relevante papel en los momentos de la conquista cristiana.

Desde este castillo siguió el califa almohade el camino de época romana del valle del Vinalopó en dirección a Murcia, pasando por otras importantes fortalezas. En este período surgen nuevos enclaves defensivos a lo largo de todo este valle, y se asiste a una repoblación del mismo por emigrantes musulmanes venidos de las tierras conquistadas por los cristianos en Aragón y Norte de Valencia. ${ }^{38}$

La importancia geopolítica de Villena, como lugar que controla el cruce de la Vía Augusta con el Camino de Aníbal, la determinará como una de las cabezas del sistema.

\subsubsection{Peñas de San Pedro}

El castillo de Peñas de San Pedro, con su extenso dominio visual ha sido tradicionalmente una de las puertas que controla una importante vía de entrada a Murcia, pues posee un control directo del importante camino empedrado que conducía desde Chinchilla a Hellín y Cartagena, siendo su llave más se-

fī jabar al-aqțār" d’Ibn 'Abd al-Mun'im al-Himyarī, Leiden, 1938, ár.: 112; trad.: 138; ed. crít. ár. completa de Iḥsān 'ABBĀS, Beirut, ed. Librairie du Liban, 1975, p. 174-175. A tan interesante personaje y a la gran importancia de la frontera de Chinchilla en el s. VII/XIII pensamos dedicarle un estudio próximamente, ampliando estos datos.

37 Rafael AZUAR: «El panorama de la Arqueología Medieval en los Valles Alto y Medio del Vinalopó», Lvcentvm, 2 (1983), pp. 349-383. Idem.: «Aspectos simbólicos de la arquitectura militar almohade. El falso despiece de sillería y las bóvedas de arcos entrecruzados», en P. CRESSIER; M. FIERRO y L. MOLINA (eds.): Los Almohades. Problemas y perspectivas, Madrid, ed. Casa de Velázquez, 2005, vol. I, pp. 123-147.

$38 \mathrm{M}^{\mathrm{a}}$. Jesús RUBIERA: Villena en las calzadas romana y árabe, p. 56. 
gura. ${ }^{39}$ Por ello, cuando es tomado efímeramente por los cristianos, el hecho causó enorme preocupación en los habitantes de Murcia.

A causa de ello -como refiere con detalle al-Himyarī- Ibn Hūd alcanzó tanto renombre entre los musulmanes murcianos con la toma del hiṣn, o fortaleza, de Šanfïruh/Peñas de San Pedro en el 614/1217.8, con una tropa de 500 soldados. ${ }^{40}$

La noticia habla de la recuperación de una de las cabezas del sistema almohade, tomada en tiempos de paz por los castellanos mediante una treta militar. Aunque no analizaremos aquí la importancia geopolítica del enclave, recordaremos que Peñas de San Pedro era una de las puertas que garantizaba la entrada a la región de Murcia a través de la montaña septentrional. Era lógico, por tanto, que los castellanos desearan abrir esa cuña hacia la capital del Segura, y era también de esperar la réplica de los murcianos, que no desearían tener esa espina amenazando su capital.

3.3.4. El sistema defensivo del río Júcar. Un sistema fronterizo durante el período almohade

Igualmente fronterizo, el río Júcar fue una importante barrera de obligado franqueo desde el Sur de Cuenca si se deseaba acceder a tierras de la Mancha Oriental. Por ello pasa a tener una especial relevancia estratégica cuando a fines del s. XII los castellanos se acercan cada vez más al Sur de la actual provincia de Cuenca.

En primer lugar hay que mencionar los castillos medievales de Jorquera y Alcalá de Júcar. El control visual que se ejerce desde la fortaleza de Jorquera abarca una vasta cantidad de territorio. Desde lo alto del castillo se divisa panorámicamente una buena porción del valle del Júcar y de los caminos que, viniendo de Iniesta (como el de "las Carriladas") descienden por las inmediaciones de la población hacia el puente, y continúan en dirección a Chinchilla.

39 Peñas de San Pedro, situada sobre la vía de época romana Cartagena-Toledo, ha sido tradicionalmente una de las puertas que controla las comunicaciones entre la vega de Murcia, y la Mancha Oriental, a través de Hellín y el valle del río Segura. Vid. Aurelio PRETEL MARÍN: El castillo de Peñas de San Pedro, del encastillamiento al villazgo (siglos X-XVI), Alcaraz, ed. Ayuntamiento de Alcaraz/Instituto de Estudios Albacetenses "Don Juan Manuel", 2005, 224 pp.

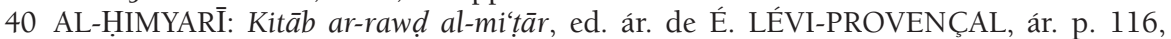
trad. 142-143; ed. crít. ár. completa de Iḥsān 'ABBĀS, 1975, p. 347. Vid. Aurelio PRETEL MARÍN: Conquista y primeros intentos de repoblación del territorio albacetense, Albacete, ed. Instituto de Estudios Albacetenses / C.S.I.C., 1986, p. 109. 
El castillo de Alcalá de Júcar, por su topónimo, es de seguro origen islámico, pero las primeras noticias que tenemos datan del siglo XII. Aún más interesantes son los restos de una población que se encuentran en el Cerro de la Horca, al otro lado del cauce del Júcar y enfrente de la actual población, despoblado adjunto a una prominencia conocida como El Mirador. Este despoblado lo hemos identificado con el lugar de Qalaṣa, que menciona al-Idrīsī en el siglo VI/XII. ${ }^{41}$

Como tercera cabeza de la frontera del Júcar hay que mencionar la citada por las fuentes como cueva de Garadén, cuyo topónimo interpretamos como Gār al-'Ayn "cueva de la fuente", ${ }^{42}$ cuya primera mención data del siglo XIII. Es una enorme abertura sobre la alta pared vertical de un encajonado meandro del río Júcar. Además de la cueva de Garadén hay otra serie de cavernas que llaman nuestra atención, por su configuración especial y su relación visual con ella. Los datos de las fuentes castellanas ${ }^{43}$ inducen a pensar que estas cavernas con construcciones fueron en los ss. XII-XIII atalayas de vigilancia coordinadas entre sí y con torres de vigilancia de los pasos del río.

\subsubsection{Alcaraz}

La primera de las descripciones que tenemos de su castillo la ha legado Ibn Ṣāhib al-Ṣalā; al referir la campaña del ejército almohade de 567/1172, dice que en su itinerario acudieron a tomar el castillo de Alcaraz, en poder de Ibn Mardanīš y de sus mercenarios cristianos. La descripción del enclave como

41 Cfr. Francisco FRANCO SÁNCHEZ: «En torno de la ubicación de la fortaleza islámica de Qalașat: ..», op. cit. Leonardo VILLENA PARDO: «Noticias históricas y técnicas sobre la hoz del Júcar y sus castillos», Congreso de Historia del Señorío de Villena. Albacete 23-26 octubre 1986, Albacete, ed. Instituto de Estudios Albacetenses / C.S.I.C. (1987), pp. 423-433.

42 Una interpretación alternativa del topónimo Garadén es la de Alfonso CARMONA GONZÁLEZ: «Garadén y otros topónimos del antiguo Señorío de Jorquera», La Cueva de La Camareta (Agramón, Hellín - Albacete). Antigüedad y Cristianismo. X. Ed. de A. González Blanco, R. González Fernández, M. Amante Fernández, Murcia, ed. Universidad de Murcia / Comunidad de Castilla La Mancha / Ayuntamiento de Hellín, vol. X, 1993, pp. 609-612, quien lo deriva de GRADĀNUS "de los escalones", derivado de GRADUS "paso, peldaño" mediante el sufijo adjetivo -ĀNUS, transformado por etimología popular en Gār Ādam "la cueva de Adán".

43 Reimpresión de la edición de la Crónica General de Ramón MENÉNDEZ PIDAL con introducción y estudio de Diego CATALÁN: Primera Crónica General de España, Madrid, ed. Gredos / Seminario Menéndez Pidal, 1977, vol. II, 688. Traducción de la Historia de Rodrigo JIMÉNEZ DE RADA por J. FERNÁNDEZ VALVERDE: Rodrigo Jiménez de Rada. Historia de los hechos de España, Madrid, ed. Alianza Editorial, 1989, p. 306. 
lugar privilegiado, y de su rica vega cuadra perfectamente con la presencia de restos de hábitat desde la época romana. Este castillo de Alcaraz disponía (como todos los anteriormente referidos) de una amplia red de atalayas que configuraba un conjunto defensivo reticular centrado en él.

Como acceso a las montañas septentrionales de Murcia, adquirirá este enclave una especial importancia. Así Aḥmad Ibn 'Alī Maḥallī Ibn Zanbal (s. $\mathrm{X} / \mathrm{XVI}$ ) en su geografía general titulada Tuhfat al-mulūk recoge del río Mundo que «este agua discurre seguidamente hacia el este y pasa por la alquería de Mesones (Mîchoûnech = Mī̌sūniš); Este lugar fue la primera plaza fronteriza de los musulmanes». ${ }^{44}$ Aunque no se diga la época en que se enmarca esta circunstancia, vuelve a aludir a la conquista cristiana de la montaña de Murcia.

Durante más de medio siglo, el castillo de Alcaraz, re-configurado en sus defensas por los almohades, resistirá como bastión y salvaguarda de la montaña murciana. Tras su toma por el infante Alfonso, no se demorará mucho la caída de la propia capital de la antigua cora de Tudmīr, puesto que Alcaraz es un importante enclave que sella otro de los caminos de entrada hacia Murcia a través de la sierra.

\subsubsection{Segura de la Sierra}

La fortaleza de Segura, a partir de la época taifal pasa a tener una relevancia más notable, si cabe, que en épocas anteriores. Su región, ampliamente poblada, y su elevado castillo, se encontraban en una zona de denso poblamiento, controlando igualmente el que posiblemente sea el más importante camino que viniendo de Jaén penetra en las serranías murcianas hasta la misma capital. Segura, es denominada por las fuentes árabes como «Puerta del Šarq al-Andalus», puesto que por ella se entraba a las rutas de montaña por las que se accedía desde la Bética a Murcia y Cartagena.

En un intento de precisar más aún cuáles pudieron ser estas fortalezas dependientes de Segura, Joaquín Vallvé considera como dependientes de Segura de la Sierra: Férez (Farǐs) y Socovos de Yeste (Šaqubuš), aunque muchas otras fortalezas dependieron de ella. ${ }^{45}$

44 Versión francesa de F. FAGNAN: Extraits inédits relatifs au Maghreb (Géographie et Histoire), Argel, ed. Tipographie Jules Carbonel, 1924, p. 144.

45 Vid. Joaquín VALLVÉ: «La división territorial de la España musulmana. La Cora de Jaén», Al-Andalus, 34, n. 1 (1969), p. 58. 


\section{UNA LÓGICA GEOPOLÍTICA PARA LA CONQUISTA CASTELLANA DE LA MANCHA ORIENTAL Y MURCIA}

La conquista de las tierras de la Mancha Oriental se llevó a cabo esencialmente en dos fases. En primer lugar, se conquista el sistema del Júcar, con sus pasos y su sistema defensivo de cuevas y atalayas. El dominio de la importante fortaleza de Alarcón por Alfonso VIII garantizó el control tanto del eje vial Toledo-Valencia, a través de Iniesta, como los accesos al valle fluvial del Júcar. Éste, tras larga contienda acabará pasando a manos castellanas.

Años después, provenientes de la Mancha central, y ya no desde el norte, los castellanos necesitan tomar la cabeza del sistema defensivo almohade que era Alcaraz. Tras caer esta ciudad, la seguirán todas las septentrionales al Camino de Aníbal. A partir de este momento, la conquista de Peñas de San Pedro marcará una cuña en dirección a Murcia que permitirá tomar primeramente los castillos de la vía de montaña paralela a la de Cartagena a Toledo

Una vez aislada la fortaleza de Chinchilla, no tardará ésta en caer. La mejor muestra de la importancia del enclave chinchillano lo aporta el hecho de que tras su conquista en el 1242 cayeron como un castillo de naipes Almansa primero, y luego por el boquete abierto hacia Murcia: Liétor, Letur, Férez, Socovos, Yeste y Taibilla. Es decir que, ya con la libertad de penetración hacia la Mancha Oriental, los castellanos acceden a los importantes castillos de la vía islámica paralela a la otra de Cartagena-Toledo (que se hallaba defendida por más sólidas defensas). Se hacen, por tanto, con la mayor parte de la Mancha Oriental, pero, más importante aún, con el control del nudo viario chinchillano, asegurándose los accesos hacia Murcia y Valencia.

Aunque conformada por otras fortalezas esta frontera, será Chinchilla, la más fuerte, la central, la última en caer, la más importante, la que aseguraba el camino hacia el levante valenciano y murciano desde la Mancha y desde Cuenca. Tras la caída de Chinchilla vino la de la sierra murciana, y la de la propia capital.

Finalmente, tras tomar los cristianos Chinchilla y Alcaraz, la penetración a través de la fortificada y segura vía de Cartagena Hellín-Murcia hará que caigan todas las fortalezas del reino $h \bar{u} d \bar{i}$.

Evidentemente las circunstancias ayudaron al infante Alfonso a la toma de Murcia; seguramente le hubiera costado algunos años y muchas más dificultades si no se la hubieran ofrecido en bandeja y él no hubiera aceptado gustosa y sagazmente la oferta. 